\title{
Numerical Investigation of a Liquid-Gas Ejector Used for Shipping Ballast Water Treatment
}

\author{
Xueguan Song, ${ }^{1,2}$ Maosen Cao, ${ }^{3}$ Wonhyup Shin, ${ }^{2,4}$ Wenping Cao, \\ Sanghoon Kang, ${ }^{2,4}$ and Youngchul Park ${ }^{2}$ \\ ${ }^{1}$ School of Electrical and Electronic Engineering, Merz Court, Newcastle University, Newcastle Upon Tyne NE1 7RU, UK \\ ${ }^{2}$ Department of Mechanical Engineering, Dong-A University, Busan 604-714, Republic of Korea \\ ${ }^{3}$ Department of Engineering Mechanics, Hohai University, Nanjing 210098, China \\ ${ }^{4}$ NK Co., Ltd., Shinpyeong-dong, Saha-gu, Busan 604-030, Republic of Korea
}

Correspondence should be addressed to Youngchul Park; parkyc67@dau.ac.kr

Received 31 October 2013; Revised 24 February 2014; Accepted 19 March 2014; Published 4 June 2014

Academic Editor: Yonghong Wu

Copyright (c) 2014 Xueguan Song et al. This is an open access article distributed under the Creative Commons Attribution License, which permits unrestricted use, distribution, and reproduction in any medium, provided the original work is properly cited.

\begin{abstract}
Shipping ballast water can have significant ecological and economic impacts on aquatic ecosystems. Currently, water ejectors are widely used in marine applications for ballast water treatment owing to their high suction capability and reliability. In this communication, an improved ballast treatment system employing a liquid-gas ejector is introduced to clear the ballast water to reduce environmental risks. Commonly, the liquid-gas ejector uses ballast water as the primary fluid and chemical ozone as the secondary fluid. In this study, high-pressure water and air, instead of ballast water and ozone, are considered through extensive numerical and experimental research. The ejector is particularly studied by a steady three-dimensional multiphase computational fluid dynamics (CFD) analysis with commercial software ANSYS-CFX 14.5. Different turbulence models (including standard $k-\varepsilon$, RNG $k-\varepsilon$, SST, and $k-\omega$ ) with different grid size and bubble size are compared extensively and the experiments are carried out to validate the numerical design and optimization. This study concludes that the RNG $k-\varepsilon$ turbulence model is the most efficient and effective for the ballast water treatment system under consideration and simple change of nozzle shape can greatly improve the ejector performance under high back pressure conditions.
\end{abstract}

\section{Introduction}

Ballast water is a huge amount of water (sometimes millions of gallons on a large ship) stored in the long-distance passenger and freight ships to provide momentum for ship stability. When the ship reaches its destination, ballast water needs to be discharged and renewed for the next journey. However, the discharges ballast water usually contains a wide range of exotic species such as animals, plants, bacteria, and viruses, which may pose a threat to the local marine environment [1]. These foreign materials often include invasive exotic species that can cause extensive ecological damage and economic losses to aquatic ecosystems. The worldwide concern over the potential harm of ecosystems from shipping ballast water has resulted in the development of a range of treatment systems to minimize these environmental risks. Currently, ballast water treatment solutions can be classified into four types: mechanical treatment, physical treatment, chemical treatment, and a combination of them [1-3]. Mechanical treatment uses fine filters to remove small immature young eggs of invasive species or uses high pressure jet to kill them. Physical treatment uses heat, ultraviolet, sonic, and other radiations to kill organisms. Chemical treatment kills existing organisms with chlorine bleach and other toxic chemicals. The combination of them has two or more treatment methods to clear the ballast water. Each of them has its advantages and disadvantages.

In the conventional ozone treatment systems, ozone gas is directly bubbled into the water which decomposes and reacts with chemicals. It is very effective to kill microorganisms, but not so at killing larger organisms. In order to kill both large organisms and microorganisms, a new ozone treatment system needs to be developed. Figure 1 shows the diagram 


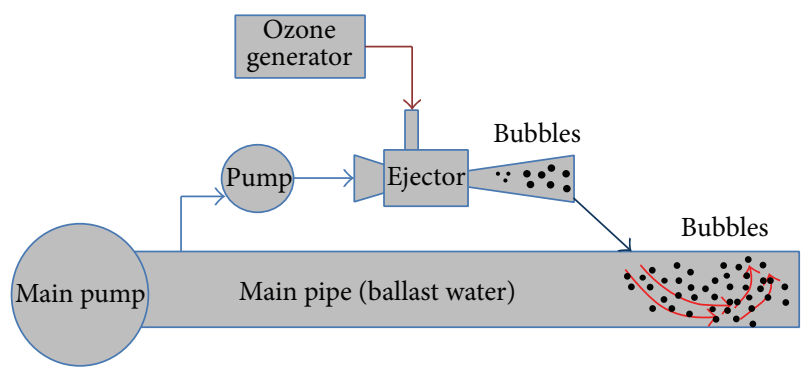

FIGURE 1: Schematic of the proposed ejected ozone ballast water treatment system.

of the proposed ballast water treatment system in this work. This system still employs ozone to kill the microorganisms. However, ozone is no longer directly pumped into the ballast water but is absorbed and ejected into ballast water by an ejector (see Figure 2). Specifically, a small amount of ballast water from the main pipe is pumped as the primary fluid through the ejector to produce a lower pressure in the suction chamber of the ejector, which absorbs ozone as the secondary fluid into the ejector and then ejects it into the downstream of the main pipe to clean the ballast water. Microorganisms are killed by an appropriate mixed fluid downstream, whilst large organisms are killed by the high-velocity impact of the ejected flow. This design has advantages of high efficiency in producing intense mixing flow and a high interfacial area for generating small bubbles to rapidly treat a large volume of ballast water. However, the main disadvantage is that the efficiency of this system is strongly dependent on the performance of the ejector. If inappropriately designed or equipped with a high back pressure, the ejector will not absorb enough ozone to treat the discharged ballast water, resulting in microorganism survivals and their escape to the local water.

An ejector can be single-phase (e.g., liquid-liquid and gas-gas ejector) or multiphase (e.g., liquid-gas and liquidsteam ejectors) [4-13]. For example, detailed experiments and computational fluid dynamics (CFD) numerical studies were undertaken to understand the hydrodynamic characteristics of the ejector geometry [6]. These CFD models provide an insight into the ejector performance under different operating conditions. Test results show that there is an optimum ratio of the nozzle area to the throat area (area ratio), at which the liquid entrainment rate is the highest. Another study investigated the effects of the ejector geometry and the operating conditions on the hydraulic characteristics in a rectangular bubble column with a horizontal flow ejector [7]. It is found that the gas suction rate increases with the liquid circulating rate in the multiphase CFD simulation with the mixture model and the experiments. However, the gas suction rate decreases as the liquid level increases in the column and nozzle diameter. However, there is no research reporting the use of a liquid-gas ejector in ballast water treatment system, relevant numerical, or experimental research. The aim of this work is to introduce a new type of the ballast water treatment system based on a liquid-gas ejector and then utilizes both experimental and computational fluid

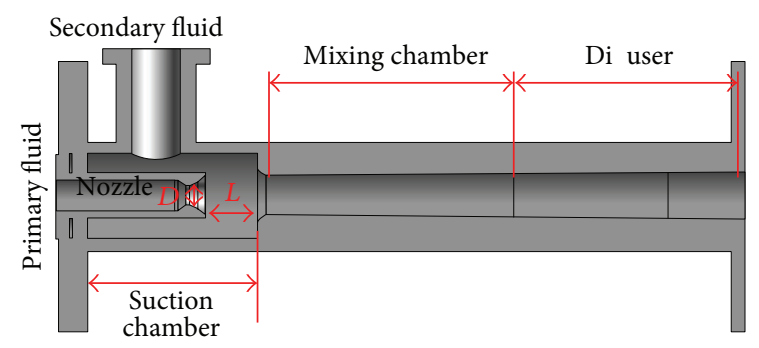

FIgURE 2: The liquid-gas ejector for the ballast water treatment.

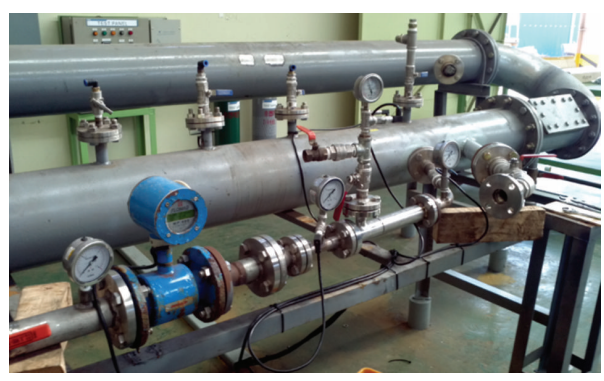

FIGURE 3: Experimental facility.

dynamics (CFD) methods for optimizing the efficiency and effectiveness of the ballast water treatment. The experimental results are used to verify the CFD simulation for selecting the best model for this research.

\section{Experimental Setup}

An experimental facility for the real-world application is shown in Figure 3. In the experiments, air is used in place of ozone as the secondary fluid; water is employed in place of ballast water as the primary fluid, and a check valve is installed on suction port to prevent back-flow, for demonstration purposes. The whole system is composed of the main pipe, the pump, and the ejector. The ejector is horizontally equipped with the main pipe, which maintains a constant pressure and allows water to circulate. The pressure of the fluid circulating in the main pipe is monitored to ensure a constant back pressure. A small amount of fluid circulating in the main pipe enters the ejector nozzle by a pump; the flow rate and the pressure of the fluid coming out of pump can be measured using a water flow meter and a pressure gauge. As the primary fluid is pumped through the ejector nozzle, the pressure of the secondary fluid entering through suction chamber $\left(P_{\text {suction }}\right)$ can be measured using the pressure gauge. Another pressure gauge measures the pressure of the waterair mixture fluid at the elbow.

\section{CFD Modeling}

3.1. Governing Equation. The principle of operation of this ejector is straightforward. It begins with a high velocity liquid from the pump and accelerates the liquid at the throat where it produces a low pressure zone that draws in and entrains a suction fluid. After passing through the throat, a mixed 
fluid expands and the velocity is reduced which results in recompressing the mixed fluids by converting the kinetics energy back into the pressure energy. Therefore, the liquidgas multiphase flow is taken into account in this study. The governing equations for the two-phase flow are then given as follows.

The continuity equation for each phase is

$$
\frac{\partial}{\partial t}\left(r_{k} \rho_{k}\right)+\nabla \cdot\left(r_{k} \rho_{k} u_{k}\right)=S_{k}
$$

The momentum conservation equation for each phase is

$$
\begin{aligned}
& \frac{\partial}{\partial t}\left(r_{k} \rho_{k} u_{k}\right)+\nabla \cdot\left(r_{k} \rho_{k} u_{k} u_{k}\right) \\
& \quad=-r_{k} \nabla p_{k}+\nabla \cdot\left(r_{k} \mu_{k}\left(\nabla u_{k}+\left(\nabla u_{k}\right)^{T}\right)\right)+r_{\alpha} \rho_{k} g+M_{k}
\end{aligned}
$$

where $r_{k}, \rho_{k}$, and $u_{k}$ are the void fraction, density, and viscosity of the phase $k$, respectively. $M_{k}$ represents the sum of interfacial forces including the drag force $F_{D}$, lift force $F_{L}$, wall lubrication force $F_{\mathrm{WL}}$, turbulent dispersion force $F_{\mathrm{TD}}$, and virtual mass force $F_{\mathrm{VM}}$. The virtual mass force has been neglected in this work, since its influence is insignificant as compared with the other drag and nondrag forces for the steady-state multiphase flows [14]. $S_{k}$ denotes the phase generation rate between different phases. By assuming the continuity and momentum equations are identical for all phases, the mixture momentum equation can be defined as

$$
\begin{aligned}
& \frac{\partial}{\partial t}\left(\rho_{m} u_{m}\right)+\nabla \cdot\left(\rho_{m} u_{m} u_{m}\right) \\
& \quad=-\nabla p_{m}+\nabla \cdot\left(\mu_{m}\left(\nabla u_{m}+\left(\nabla u_{m}\right)^{T}\right)\right)+\rho_{m} g+M_{m}
\end{aligned}
$$

where the mixture density $\rho_{m}$ is defined as

$$
\rho_{m}=\sum_{k=1}^{N} r_{k} \rho_{k} .
$$

In this work, the number of phases $N=2$. Since the sum of all phases must occupy the whole domain volume, the following constraint must be satisfied:

$$
\sum_{k=1}^{N} r_{k}=1 .
$$

Similarly, the mass sources between phases must conserve:

$$
\sum_{k=1}^{N} S_{k}=1 .
$$

3.2. Turbulent Closures. The Reynolds number inside of the ejector is much greater than $10^{5}$, which shows that the flow through the ejector is turbulent. To deal with the turbulence flow, the Reynolds-averaged Navier-Stokes equations (RANS) are utilized. In this case, simulation based on RANS equations substantially reduces the computational effort in comparison with the direct numerical simulation (DNS), but the averaging procedure introduces additional unknown terms containing products of the fluctuating components. This acts like additional stresses in the fluid, so that a turbulence model is needed to close the set of equations. In this work four two-equation turbulence models named standard $k-\varepsilon$, RNG $k-\varepsilon, k-\omega$, and shear stress transport (SST) model are adopted to fulfill the aim. It should be noticed that the SST model is based on the combination of standard $k-\varepsilon$ and $k-\omega$ turbulence models in the formulation of Wilcox. The hybrid procedure consists of the $k$-equation and a special form of the $\omega$-equation, which enables changing the value of a blend factor $F_{1}$ switching between a $\omega$-equation $\left(F_{1}=1\right)$ and a $\varepsilon$-equation $\left(F_{1}=0\right)[15]$.

3.3. Computational Domain and Boundary Conditions. Figure 4 shows the grid model in ANSYS CFX 14.5. For accurate simulations, the CFD model is created at a $1: 1$ scale with the exact geometry as shown in Figure 3 . The continuous phase from the nozzle section (inlet_1) utilizes water at $25^{\circ} \mathrm{C}$, and the dispersed phase from the suction section utilizes air at $25^{\circ} \mathrm{C}$. Since the volumetric flow rate of water is set and known as constant in the experiments, a fixed flow rate of $7.009 \mathrm{~kg} / \mathrm{s}$ is used as a boundary condition at inlet_1. The inlet condition with atmospheric pressure is applied at inlet_2, preventing air and/or water from flowing out of the ejector which coincides with the physical experiment because a check valve is installed inside of the suction pipe. Inlet_3 is defined as an inlet boundary condition with a constant flow rate. The main outlet is set as the opening condition with various back pressures. In addition to the inlet and outlet conditions, all other surfaces are defined as walls under no-slip boundary conditions. The simulation is initialized with full air; that is, $r_{\text {air }}=1$. With regard to the solver algorithm, high resolution is used for the advection scheme and turbulence numerics. The convergence criteria for continuity, momentum, and transport equations are set to $10^{-4}$, as multiphase simulation is numerically difficult to converge.

3.4. Mesh and Bubble Independence. The mesh size is a virtual issue for CFD simulation because it not only significantly influences the computational accuracy but also directly determines the computational effort. Therefore a mesh independence study has to be carried out to find out the desirable mesh size, which can represent a good compromise between computational effort and accuracy. In this work, a total of five types of mesh sizes are used, namely, coarse, medium, fine, very fine, and extremely fine. Table 1 presents a comparison of these mesh sizes with different nodes and elements. Their effect on the elbow pressure and the mass flow of suction air is illustrated in Figure 5. It can be seen from this figure that the mesh size has little effect on the CFD simulation when it increases to fine mesh size and above. Therefore, the very fine mesh size is determined as 


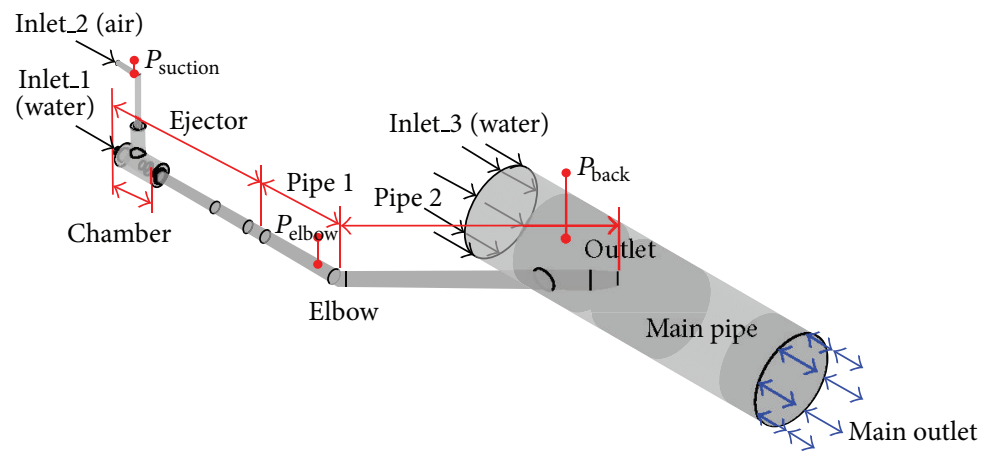

FIGURE 4: CFD model of the ejector and pipe.

TABLE 1: Five types of mesh sizes and their nodes/elements.

\begin{tabular}{lcccc}
\hline No. & Mesh & Min. size & Nodes & Elements \\
\hline 1 & Coarse & $5.00 \mathrm{~mm}$ & 72215 & 55,187 \\
2 & Medium & $1.00 \mathrm{~mm}$ & 107448 & 319182 \\
3 & Fine & $0.30 \mathrm{~mm}$ & 497,009 & $1,751,294$ \\
4 & Very fine & $0.10 \mathrm{~mm}$ & 920,163 & $3,324,958$ \\
5 & Extremely fine & $0.05 \mathrm{~mm}$ & $1,116,462$ & $6,982,431$ \\
\hline
\end{tabular}

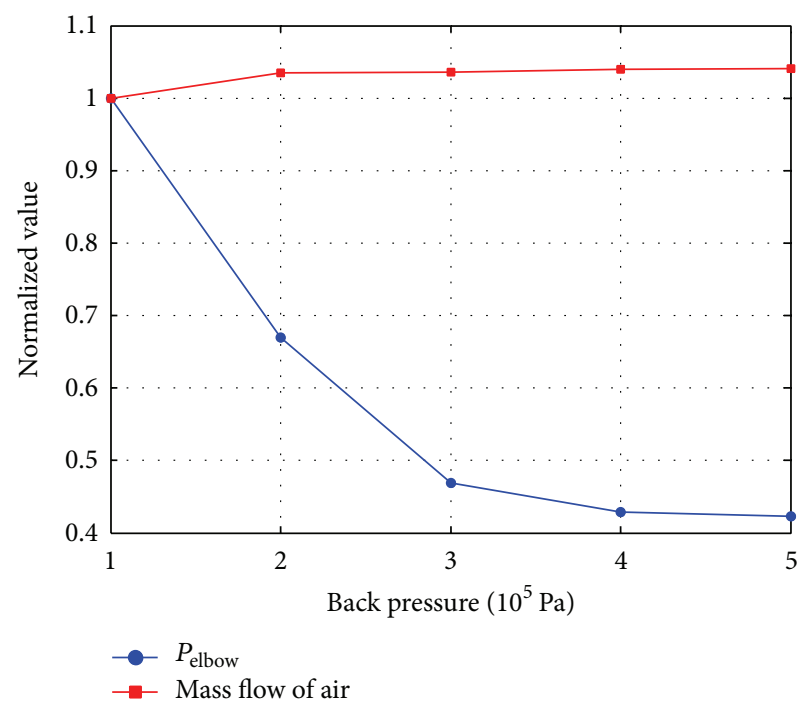

Figure 5: Mesh effect on the results.

the most appropriate size striking a balance between the computational accuracy and the computational effort.

As a large amount of discrete air bubbles are involved in this simulation, a bubble size independence study is carried out so as to identify an appropriate bubble size. Figure 6 shows the mass flow of suction air and the elbow pressure with the change of bubble sizes. It is easily concluded that bubble size has negligible effect on the results. Therefore, a classical bubble diameter of $1.0 \mathrm{~mm}$ is defined in this work, which is also in agreement with a previous study [9].

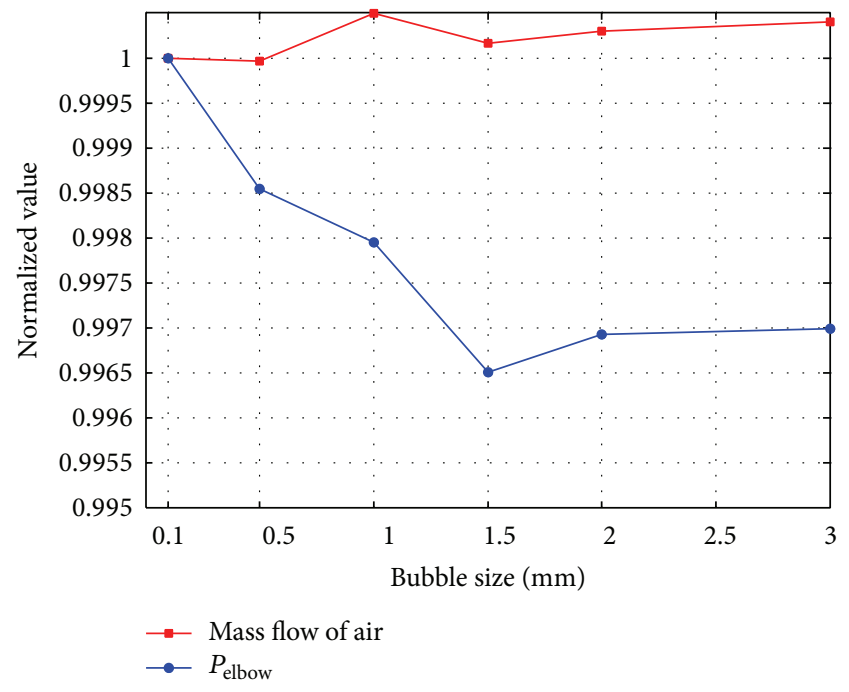

Figure 6: Bubble effect on the results.

\section{Results}

The effect of the back pressure on the suction pressure and elbow pressure is investigated in this work, and four turbulence models are also compared with the experiments to find the most appropriate one for the targeted application. As shown in Figures 7 and 8, the deviation between the CFD results and experimental results is all below $8 \%$ for the prediction of the elbow pressure and below $10 \%$ for the prediction of the suction pressure. The deviations could be attributed to the following modeling issues: (i) the application of impressible air at $25^{\circ} \mathrm{C}$ instead of the real compressible air and the exclusion of heat transfer between the different phases and (ii) the inadequacy for the mixture model and interfacial force model produced to handle the large amount of bubbles.

On the whole, the RNG $k-\varepsilon$ turbulence model is in the best agreement with experiments. Its mean that error is $3.25 \%$ for elbow pressure prediction and 3.36\% for suction pressure prediction. Next, the SST and $k-\omega$ models show less accurate results than the RNG $k-\varepsilon$ model. The standard $k-\varepsilon$ turbulence model failed to converge for any meaningful results and is thus inappropriate for the CFD analysis of the liquid-gas ejector. Therefore, the RNG $k-\varepsilon$ model is 


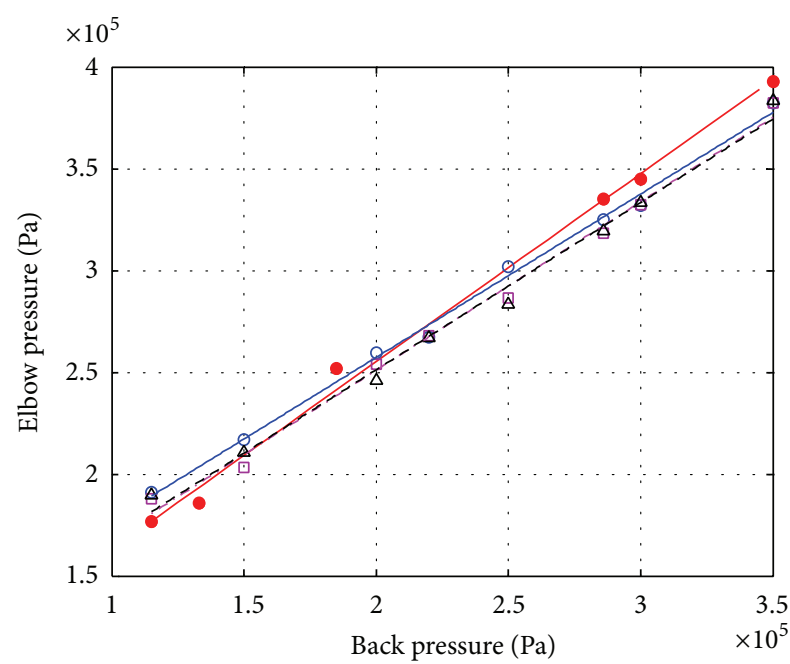

- Experimental results

- Fitted curve of experimental results

- CFD results with RNG $k-\varepsilon$ model

口 CFD results with SST model

$\Delta \quad$ CFD results with $k-\omega$ model

_ Fitted curve of RNG $k-\varepsilon$ results

...- Fitted curve of SST results

- - - Fitted curve of RNG $k$ - $\omega$ results

Figure 7: Comparison of $P_{\text {elbow }}$ with back pressures.

chosen for the multiphase ejector simulation and is used for the subsequent analysis for understanding the characteristics of the ejector. In addition, it should be noticed that the residue for each equation falls down below $10^{-5}$ when the back pressure is higher than $2.86 \times 10^{5} \mathrm{~Pa}$ (even though the default value is $10^{-4}$ ). This is due to the fact that the two-phase liquidgas problem becomes a single-phase liquid problem under a high back-pressure condition, where a wall has been placed at portion(s) of the inlet_2 to prevent fluid from flowing out of the domain.

For a pressure comparison, as the back pressure increases from $1.15 \times 10^{5} \mathrm{~Pa}$ to $2.86 \times 10^{5} \mathrm{~Pa}$, the pressure ahead of the elbow increases almost linearly from $1.9 \times 10^{5} \mathrm{~Pa}$ to $3.8 \times$ $10^{5} \mathrm{~Pa}$. The suction pressure shows a similar trend, increasing from $-7049 \mathrm{~Pa}$ to $92025 \mathrm{~Pa}$. This suggests that the flow rate of absorbed air decreases from $48.0 \mathrm{~m}^{3} / \mathrm{hr}$ to $0.0 \mathrm{~m}^{3} / \mathrm{hr}$ as shown in Figure 9. That is, no air is absorbed into the ejector when the back pressure is greater than $2.8 \times 10^{5} \mathrm{~Pa}$. In essence, the kinetic energy in the high velocity water jet is mainly transferred into the potential energy (high back pressure), leaving no extra energy to absorb the air at the ejector.

Figure 10 shows the contour of the air volume fraction at three different back pressures. It can be clearly found that as water leaves the nozzle tip, it forms a strong jet that passes through the suction chamber and mixing chamber which produce a lower pressure region to absorb the air from the suction port. A clear phase interface between water and air in the suction chamber means they are not well mixed. Air flows in the annular region between the jet of water and the ejector wall (i.e., coaxial-flow due to the high velocity water jet). As water and air flow in the same path and annularly

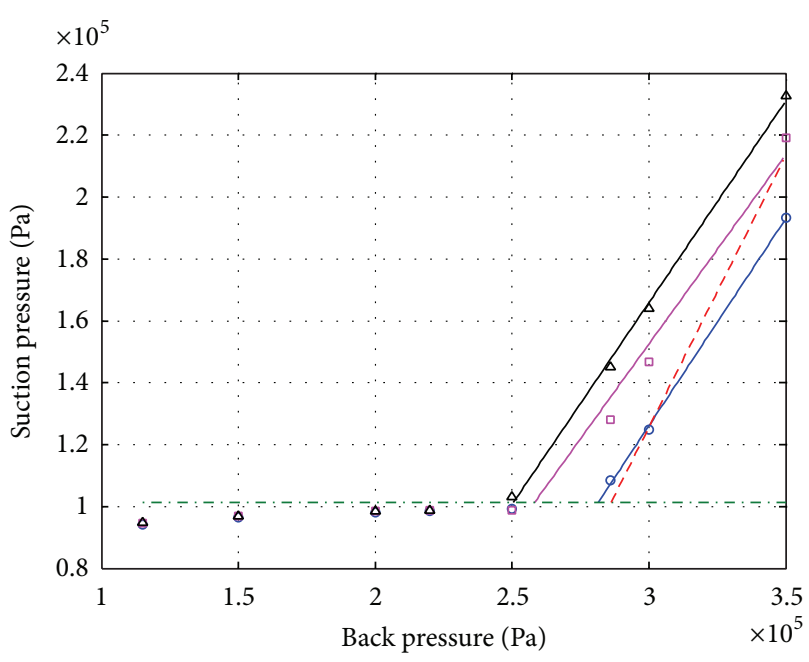

- CFD results with RNG $k-\varepsilon$ model

- CFD results with SST model

$\triangle \quad$ CFD results with $k-\omega$ model

— Fitted curve of RNG $k-\varepsilon$ results

_ Fitted curve of SST results

- Fitted curve of $k$ - $\omega$ results

- - Ambient pressure (1 atm)

- - - Fitted curve of experimental results

FIgURE 8: Comparison of $P_{\text {suction }}$ with back pressures.

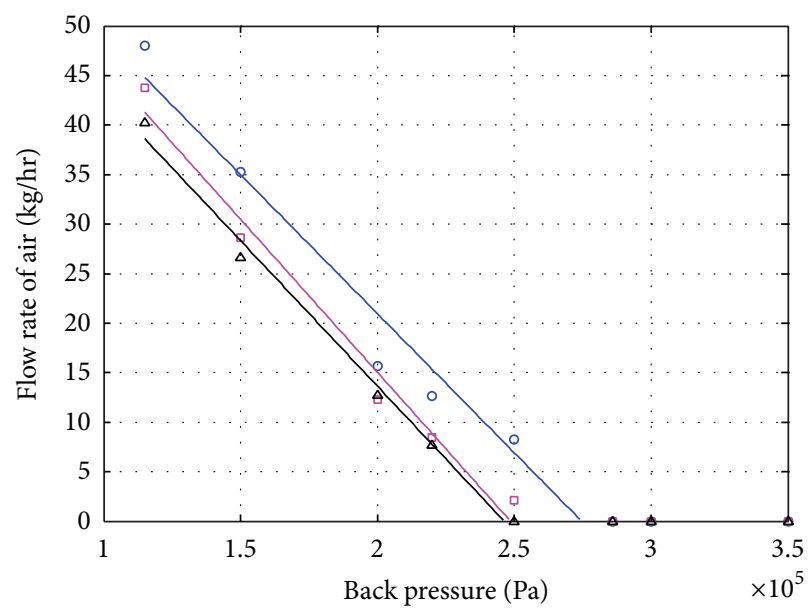

- CFD results with RNG $k-\varepsilon$ model

- CFD results with SST model

$\triangle \quad$ CFD results with $k-\omega$ model

— Fitted curve of RNG $k$ - $\varepsilon$ results

_ Fitted curve of SST results

— Fitted curve of $k$ - $\omega$ results

Figure 9: Absorbed air flow rate with back pressures.

downstream, their mixing becomes evident and intensive, which results in a large amount of air bubbles dispersed in the water. The jet intensity decreases dramatically as the back pressure increases because it needs to be transferred to pressure energy to withstand the effect of the back pressure. In turn, the decrease in the jet momentum leads to a pressure drop between the suction chamber and the ambient air. Therefore the flow rate of absorbed air drops sharply. 


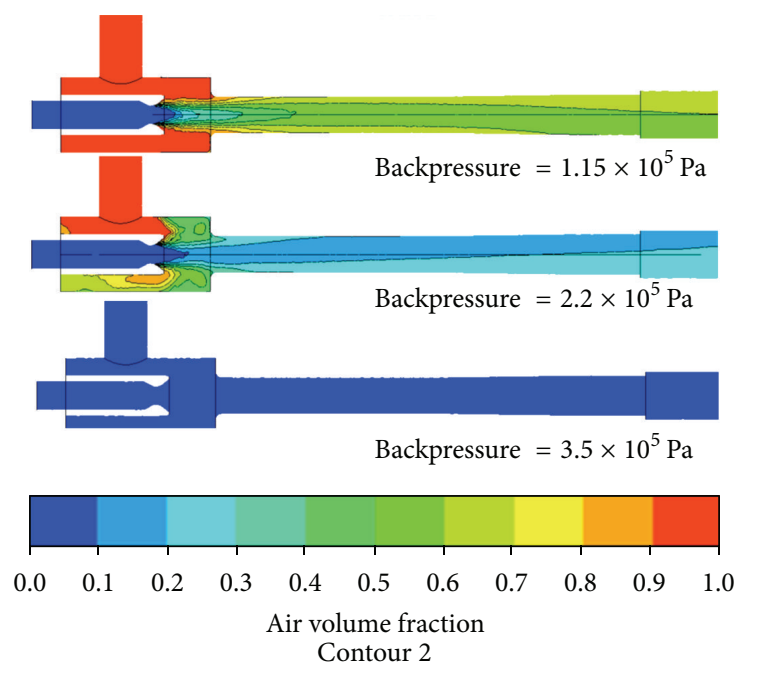

FIGURE 10: Volume fraction of air with different back pressures at the middle plane.

This ejector-based system will be used under a high back pressure condition, so its performance under high back pressure condition is of great concern. Optimization of ejector in the previous work is mainly focusing on the suction chamber and mixing chamber; this usually costs a lot of effort and time as there are too many dimensions. In this work, a quick method which only alters the nozzle shape is proposed to efficiently achieve the goal of optimization. Figure 11 shows the initial nozzle and the newly designed nozzle. The new one has a straight shape and its diameter is the same as the throat diameter of the initial curved shape. The CFD simulation of the new design has been conducted with the same mesh size, bubble size, and boundary conditions as depicted in Section 3.3.

The CFD results are shown in Figure 12. It can be found that at low back pressure condition $\left(P_{b} \leq 1.7 \times\right.$ $10^{5} \mathrm{~Pa}$ ), the suction performance is a little worse than the initial nozzle. However, when they are working under higher back pressures, the advantage of the new straight nozzle is becoming more and more evident. Specifically, at the back pressure of $2 \times 10^{5} \mathrm{~Pa}$, the absorbed air by the initial design and new design are $20.95 \mathrm{Kg} / \mathrm{hr}$ and $23.44 \mathrm{Kg} / \mathrm{hr}$, respectively, with an improvement of $11.89 \%$. At the back pressure of $2.5 \times$ $10^{5} \mathrm{~Pa}$, the absorbed air by the initial design and new design are $6.915 \mathrm{Kg} / \mathrm{hr}$ and $12.99 \mathrm{Kg} / \mathrm{hr}$, respectively, which means that an improvement of $87.85 \%$ has been achieved. The initial one will loss the capability of absorbing air at back pressure of about $2.8 \times 10^{5} \mathrm{~Pa}$, but the new design still can absorb approximately $8 \mathrm{Kg} / \mathrm{hr}$ air from the suction port at the same back pressure. The new design will stop absorbing air at the back pressure of $3.13 \times 10^{5} \mathrm{~Pa}$ eventually. This improvement can be attributed to two reasons: (1) the straight nozzle generates a less pressure loss than the curved shape, so a higher motivate energy is maintained through the nozzle; (2) a portion of the drive water diverge to the suction chamber from the nozzle due to the curved shape and block the air flow to mixing chamber, which does not happen in the straight nozzle design.

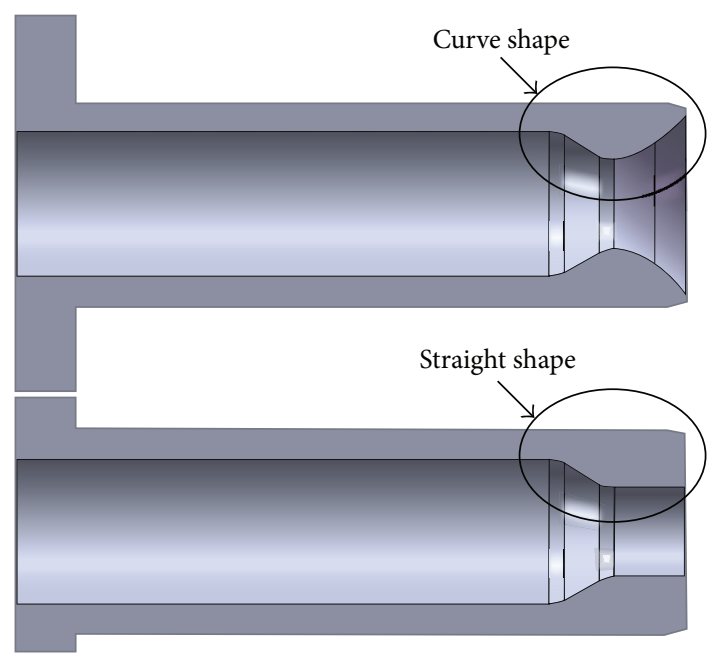

FIGURE 11: Initial nozzle and new nozzle.

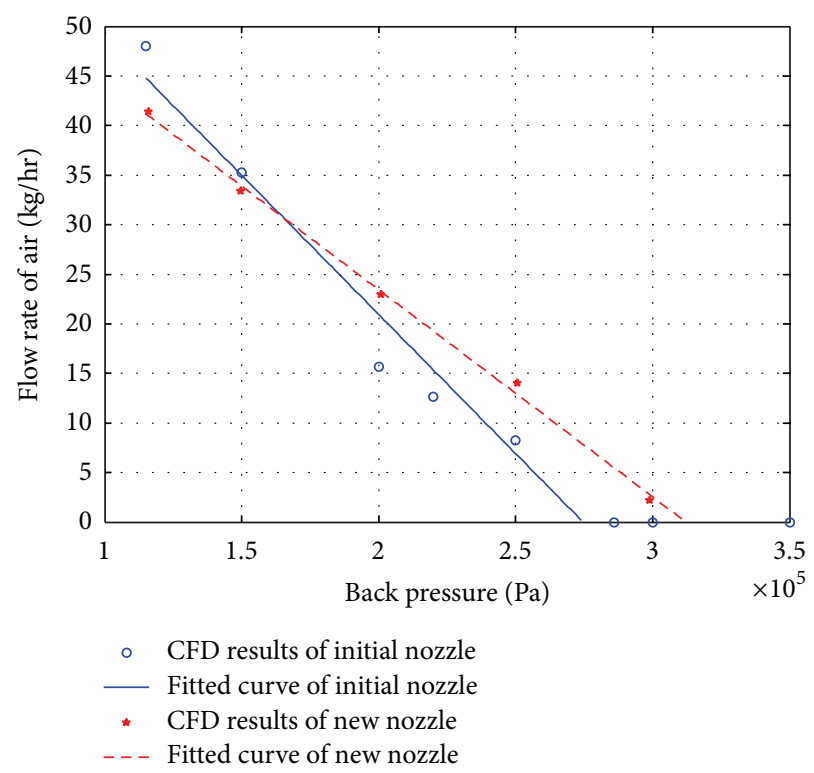

FIGURE 12: Comparison of air mass flow for different nozzles.

\section{Conclusion}

Shipping ballast water treatment is a critical process to minimize the impact of ballast water discharge on the marine environment. The paper has presented a novel ballast water treatment system with a liquid-gas two-phase ejector. Numerical simulation and experimental tests are conducted to understand the performance of the ejector. Pressures of the ejector were first examined on an experimental bench to validate CFD models with different turbulence models, followed by extensive CFD analysis. Test results on the liquidgas ejector have clearly shown that RNG $k-\varepsilon$ turbulence model with the very fine grid size is most effective striking a balance between accuracy and computational costs. CFD analysis also indicates that the initial liquid-gas ejector may lose its absorption capability when the back pressure exceeds 
2.8 bars in the ballast water treatment system. With the straight nozzle altered, the new design can efficiently improve the ejector performance at high back pressures and will not lose the absorption capability until 3.13 bar back pressure. In the further work, in-depth study on the ejector nozzle and other geometrical parameters will be carried out to find the optimal geometry for the ballast water treatment. The multiphase reaction flow will also be taken into account for understanding the mixing characteristics and the treat efficiency of ballast water.

\section{Conflict of Interests}

The authors declare that there is no conflict of interests regarding the publication of this paper.

\section{Acknowledgment}

This work was supported by Technical Center for HighPerformance Valves from the Regional Innovation Center (RIC) Program of the Ministry of Knowledge Economy (MKE).

\section{References}

[1] M. M. Abu-Khader, O. Badran, and M. Attarakih, "Ballast water treatment technologies: hydrocyclonic a viable option," Clean Technologies and Environmental Policy, vol. 13, no. 2, pp. 403413, 2011.

[2] American Bureau of Shipping, Guide for Ballast Water Treatment, American Bureau of Shipping, Houston, Tex, USA, 2011.

[3] A. H. Taylor and G. Rigby, Suggested Designs to Facilitate Improved Management and Treatment of Ballast Water on New and Existing Ships, Department of Agriculture, Fisheries \& Forestry, Canberra, Australia, 2001.

[4] A. Elgozali, V. Linek, M. Fialová, O. Wein, and J. Zahradník, "Influence of viscosity and surface tension on performance of gas-liquid contactors with ejector type gas distributor," Chemical Engineering Science, vol. 57, no. 15, pp. 2987-2994, 2002.

[5] M. T. Kandakure, V. G. Gaikar, and A. W. Patwardhan, "Hydrodynamic aspects of ejectors," Chemical Engineering Science, vol. 60, no. 22, pp. 6391-6402, 2005.

[6] S. Balamurugan, M. D. Lad, V. G. Gaikar, and A. W. Patwardhan, "Hydrodynamics and mass transfer characteristics of gas-liquid ejectors," Chemical Engineering Journal, vol. 131, no. 1, pp. 83103, 2007.

[7] M. I. Kim, O. Sin Kim, D. H. Lee, and S. Done Kim, "Numerical and experimental investigations of gas-liquid dispersion in an ejector," Chemical Engineering Science, vol. 62, no. 24, pp. 71337139, 2007.

[8] T. Utomo, Z. Jin, M. Rahman, H. Jeong, and H. Chung, "Investigation on hydrodynamics and mass transfer characteristics of a gas-liquid ejector using three-dimensional CFD modeling," Journal of Mechanical Science and Technology, vol. 22, no. 9, pp. 1821-1829, 2008.

[9] R. L. Yadav and A. W. Patwardhan, "Design aspects of ejectors: effects of suction chamber geometry," Chemical Engineering Science, vol. 63, no. 15, pp. 3886-3897, 2008.
[10] C. Li and Y. Z. Li, "Investigation of entrainment behavior and characteristics of gas-liquid ejectors based on CFD simulation," Chemical Engineering Science, vol. 66, no. 3, pp. 405-416, 2011.

[11] Y. K. Kim, D. Y. Lee, H. D. Kim, J. H. Ahn, and K. C. Kim, "An experimental and numerical study on hydrodynamic characteristics of horizontal annular type water-air ejector," Journal of Mechanical Science and Technology, vol. 26, no. 9, pp. 2773-2781, 2012.

[12] M. Šimčík, A. Mota, M. C. Ruzicka, A. Vicente, and J. Teixeira, "CFD simulation and experimental measurement of gas holdup and liquid interstitial velocity in internal loop airlift reactor," Chemical Engineering Science, vol. 66, no. 14, pp. 3268-3279, 2011.

[13] X. Song, J. Park, S. Kim, and Y. Park, "Performance comparison and erosion prediction of jet pumps by using a numerical method," Mathematical and Computer Modelling, vol. 57, no. 1-2, pp. 245-253, 2013.

[14] T. Frank, P. J. Zwart, E. Krepper, H.-M. Prasser, and D. Lucas, "Validation of CFD models for mono- and polydisperse airwater two-phase flows in pipes," Nuclear Engineering and Design, vol. 238, no. 3, pp. 647-659, 2008.

[15] D. C. Wilcox, "Reassessment of the scale-determining equation for advanced turbulence models," AIAA journal, vol. 26, no. 11, pp. 1299-1310, 1988. 


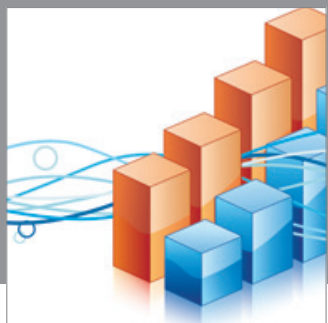

Advances in

Operations Research

mansans

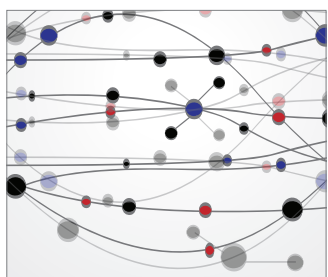

The Scientific World Journal
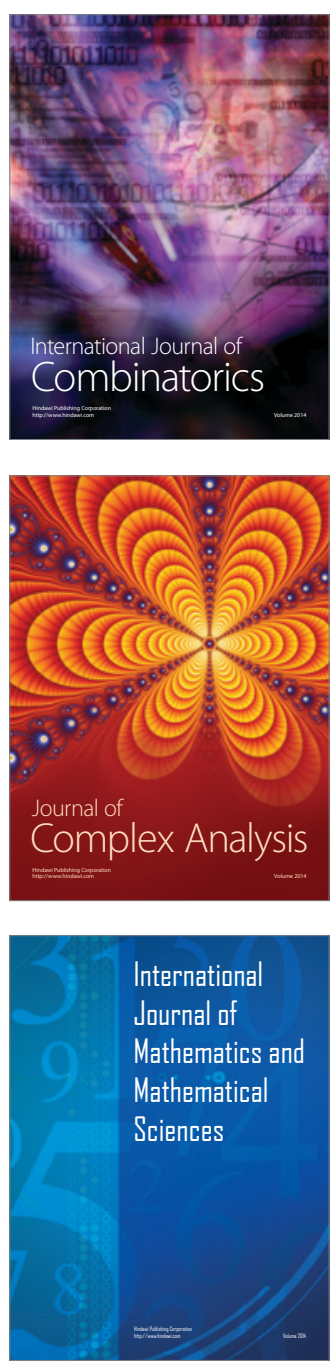
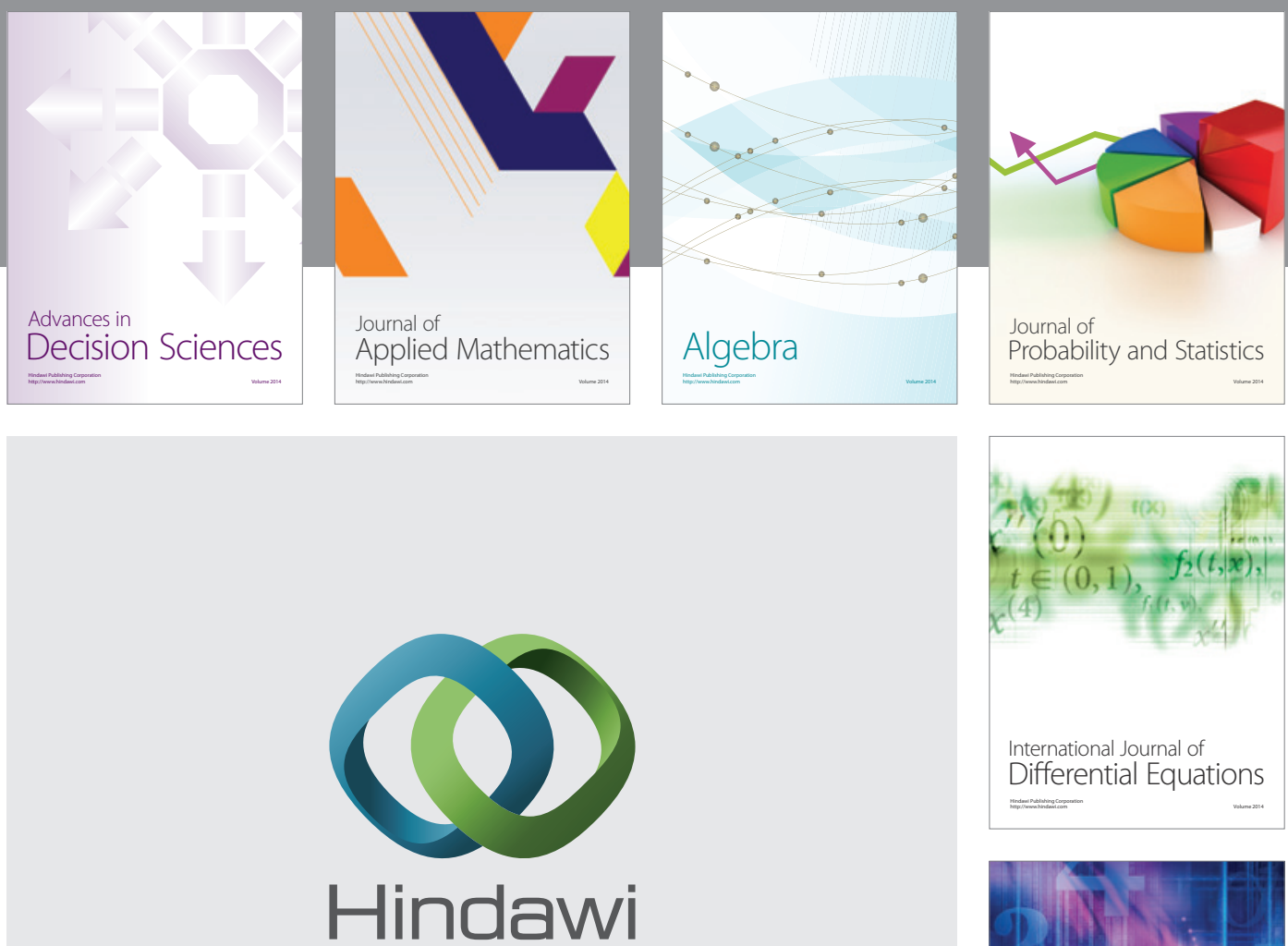

Submit your manuscripts at http://www.hindawi.com
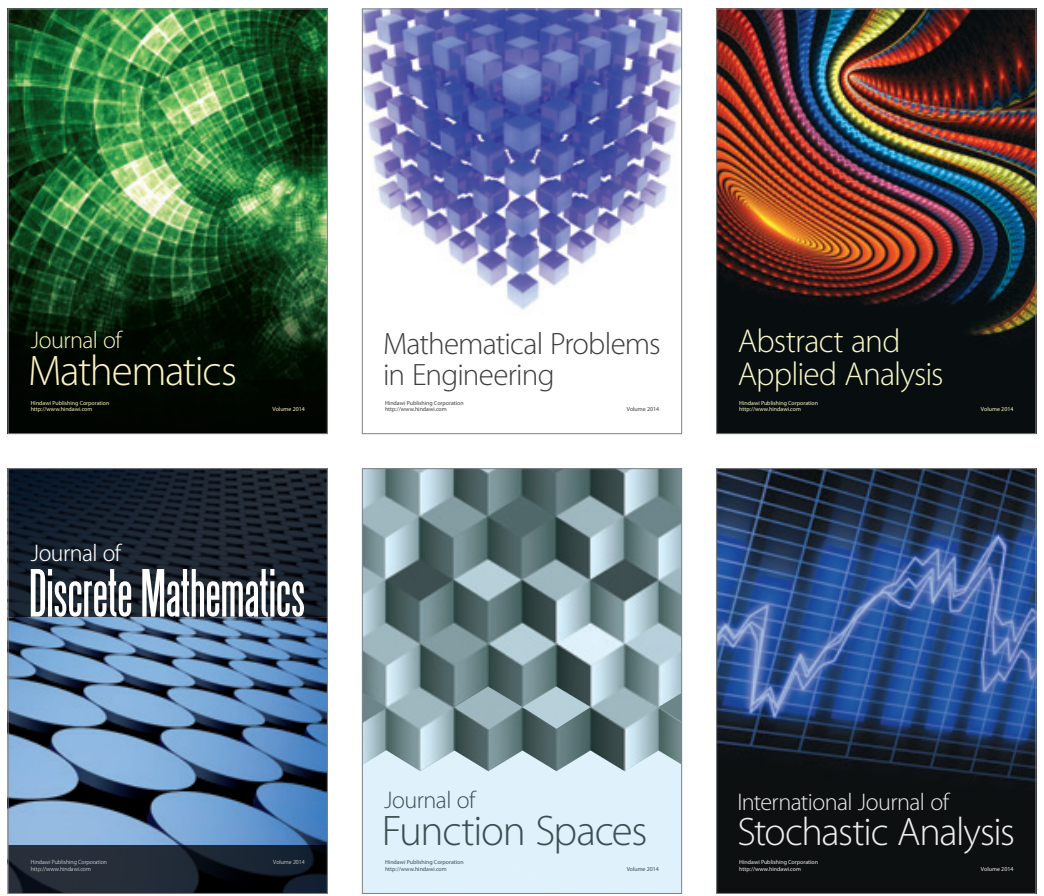

Journal of

Function Spaces

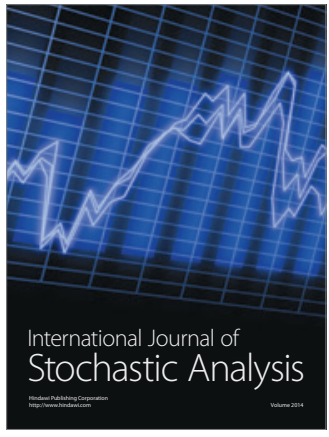

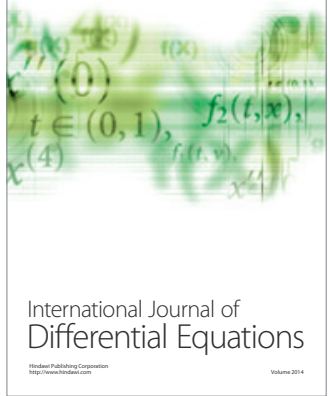
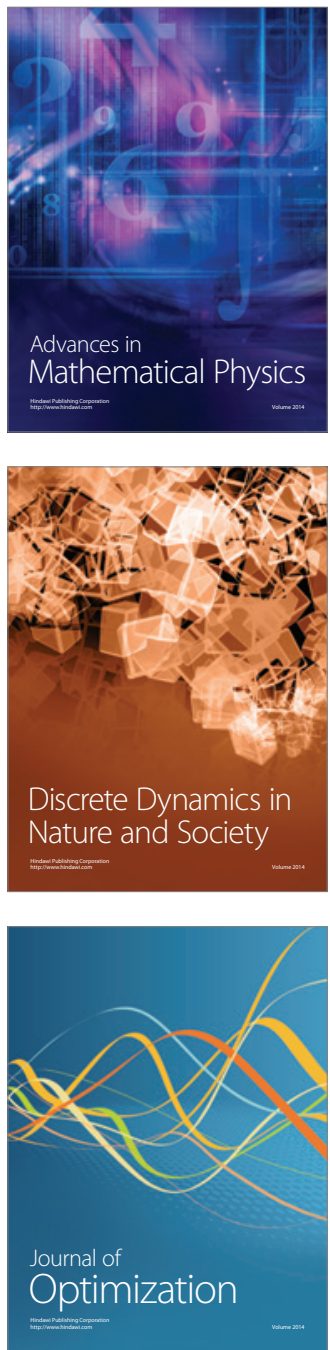